
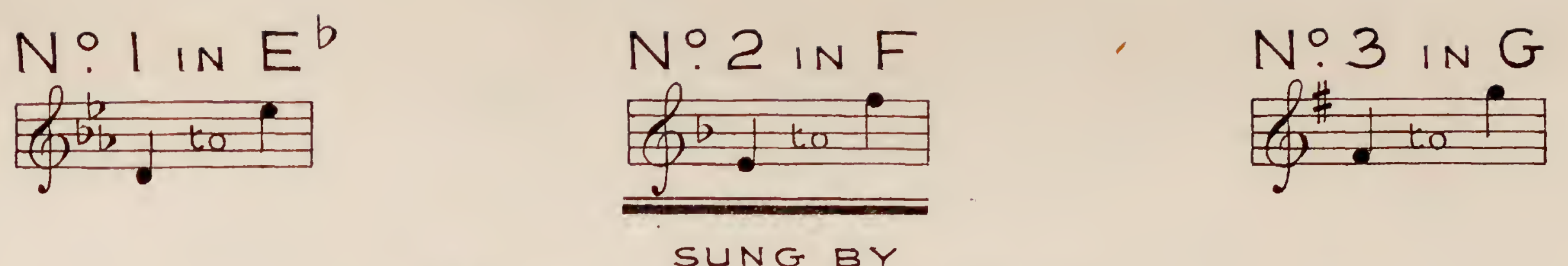

Madame Clara Butt.

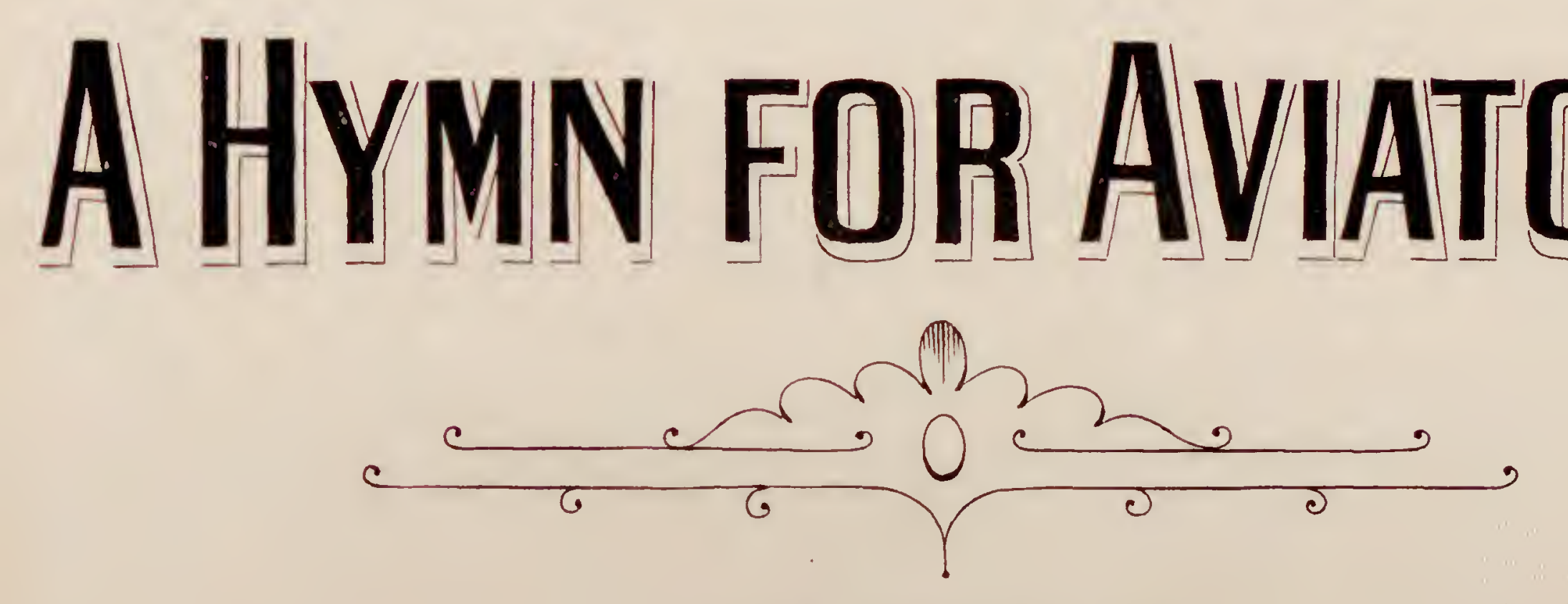

THE WORDS BY

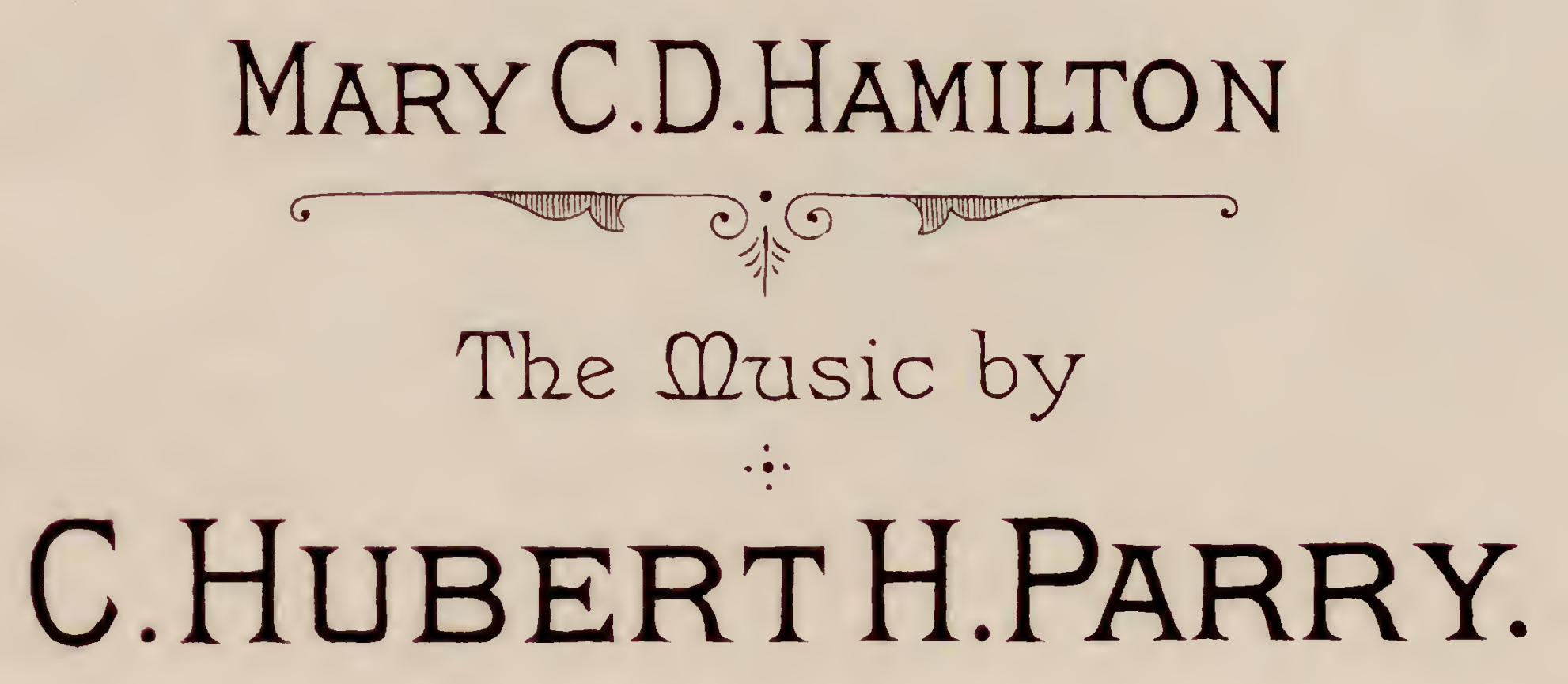

PRICE 2/:NET

"A HYMN FOR AVIATORS", FOR FOUR VOICES,IN OPEN SCORE, PRICE TWOPENCE: IN SHORT SCORE, ONE PENNY.

\title{
BOOSEY\& $C$
} 295. Regent StREet, LONDON,W. 9. EAST ITTHSTREET. AND 229.YONGE STREET.
NEW YORK.

THIS SONG MAY BE SUNG IN PUBLIC WITHOUT FEE OR LICENSE. THE PUBLIC PERFORMANCE OF ANY PARODIED VERSION. HOWEVER, IS STRICTLY PROHIBITED.

COPYRIGHT 1915 BY BOOSEY\&C. 


\section{A HYMN FOR AVIATORS.}

LORD, guard and guide our men who fly Through the great spaces of the sky, Be with them traversing the air

In dark'ning storm or sunshine fair.

Thou who dost keep with tender might The balanced birds in all their flight, Thou of the tempered winds, be near, That, having Thee, they know no fear.

Control their minds with instinct fit, What time, adventuring, they quit The firm security of land;

Grant steadfast eye and skilful hand.

Aloft, in solitudes of space, Uphold them with Thy saving grace; O God, protect our men who fly Through lonely ways beneath the sky.

MaRY C. D. Hamilton. 


\section{A HYMN FOR AVIATORS.}

Words by

MARY C. D. HAMILTON.
Music by

C. HUBERT H. PARRY.
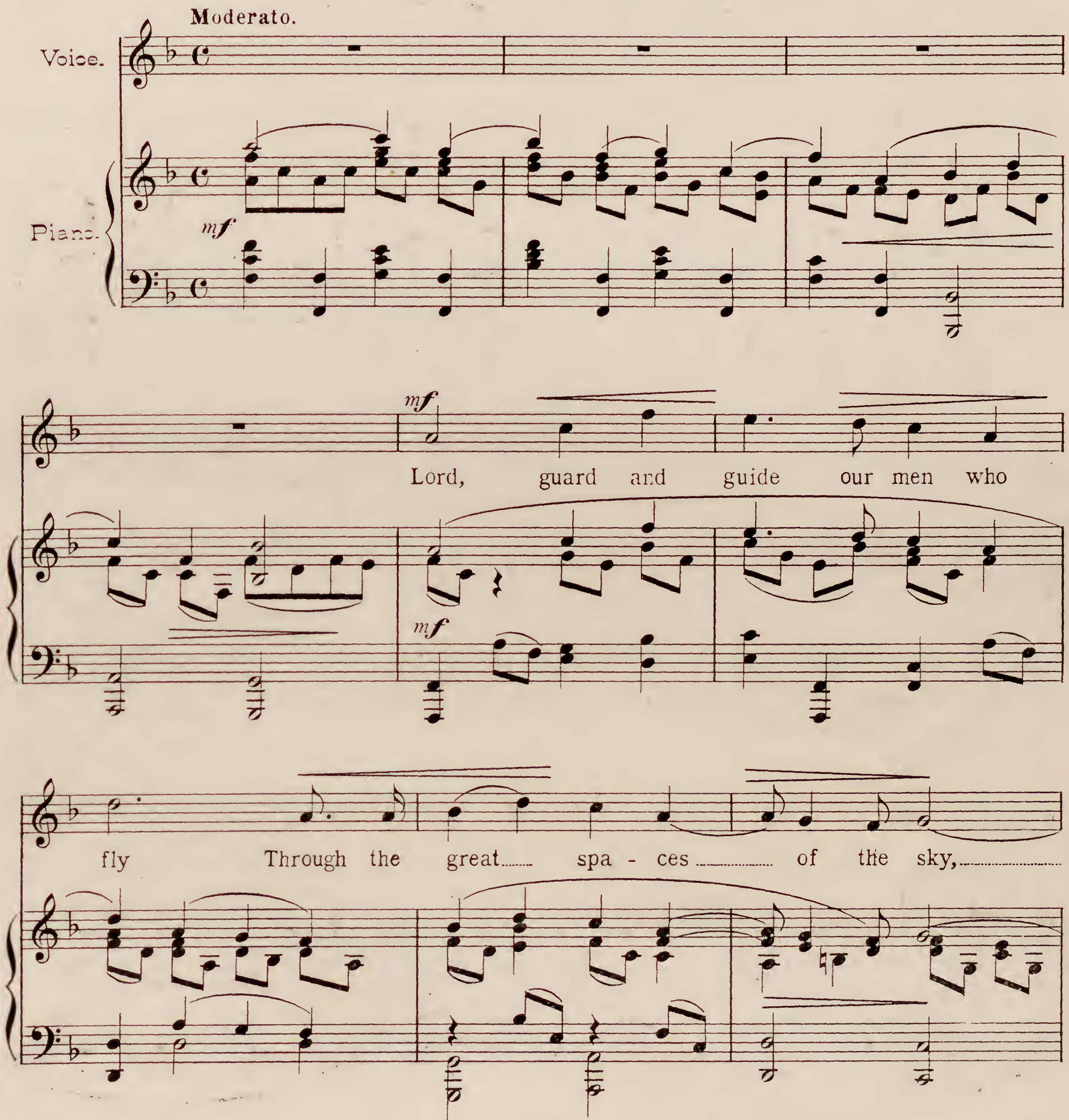


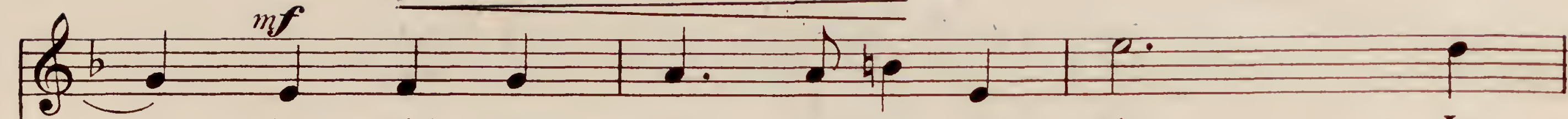
Be with them tra - vers-ing the air In

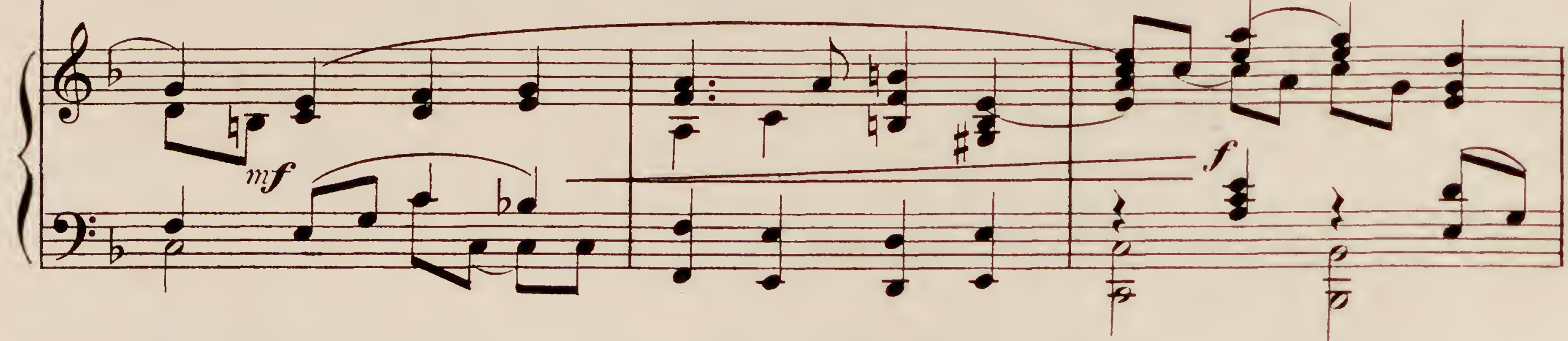
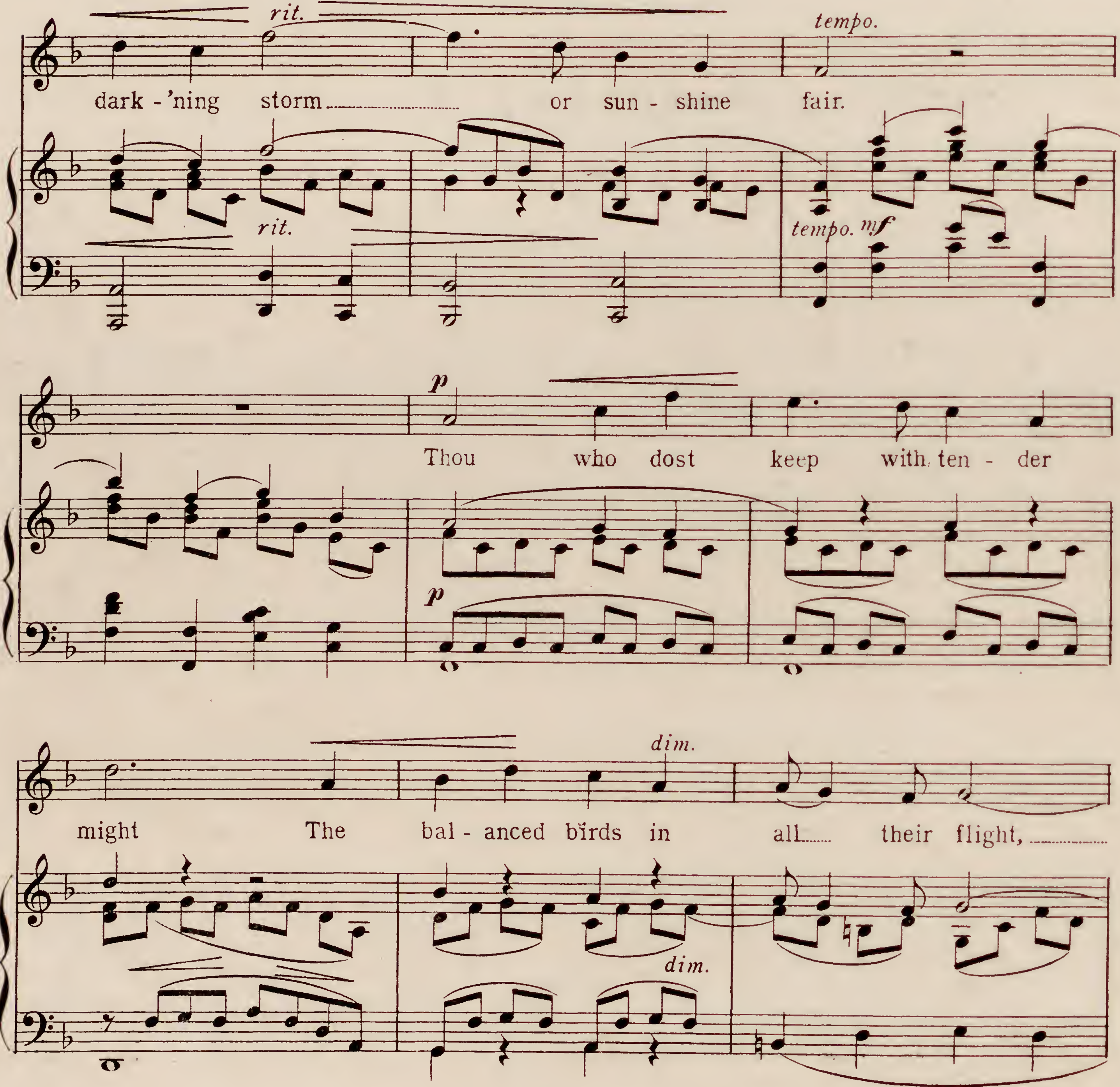

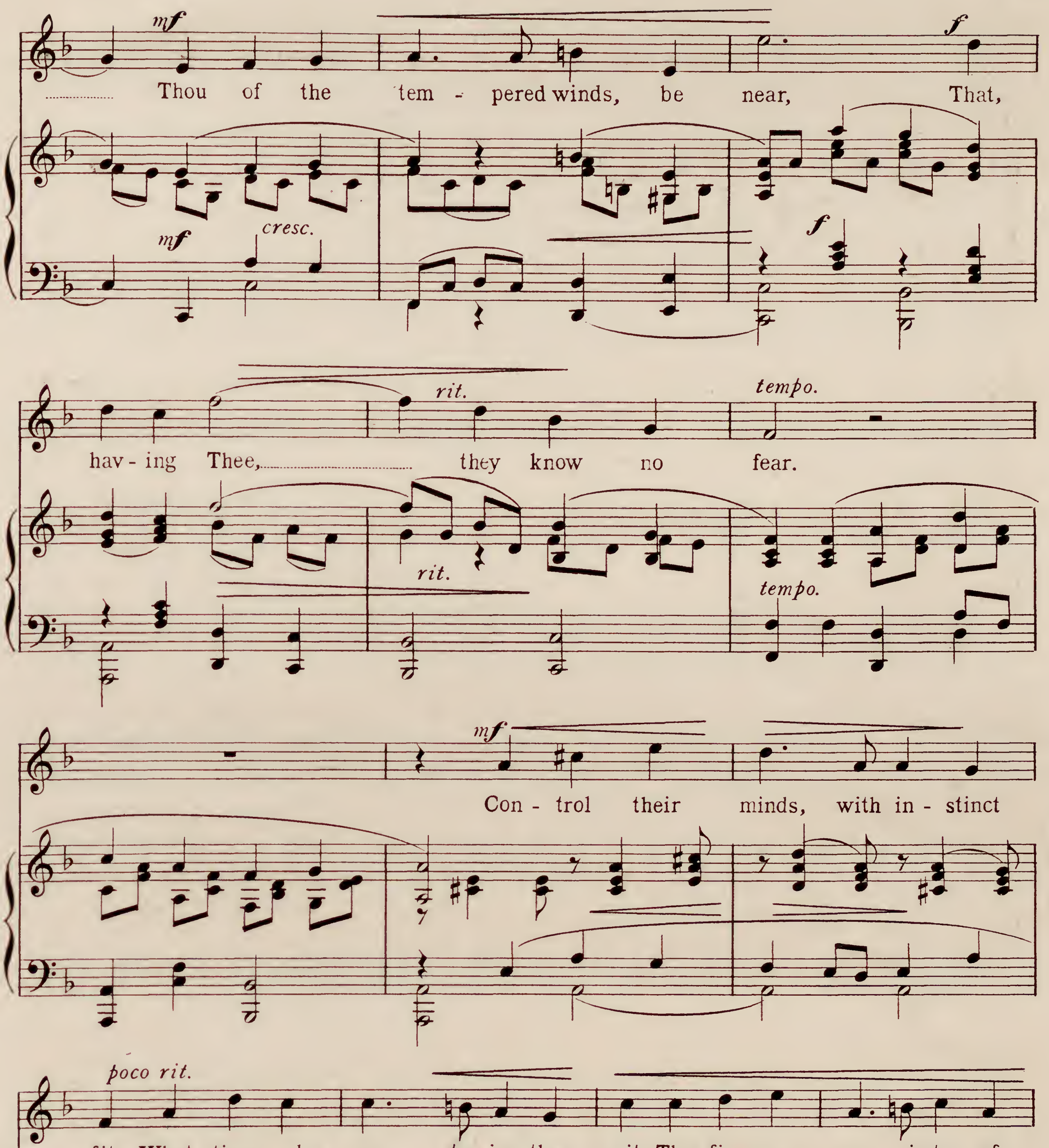

fit, What time, ad - ven - tur-ing, they quit The firm se - cu - ri-ty of

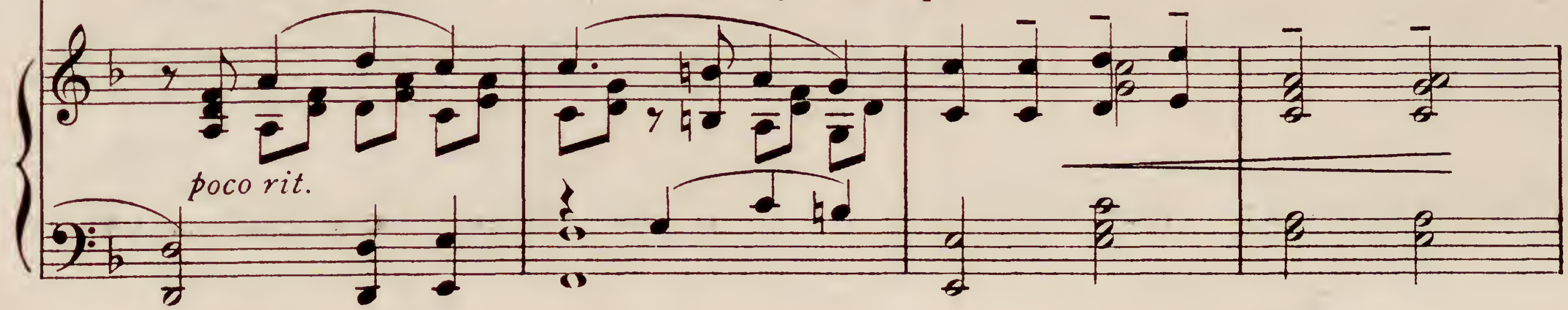



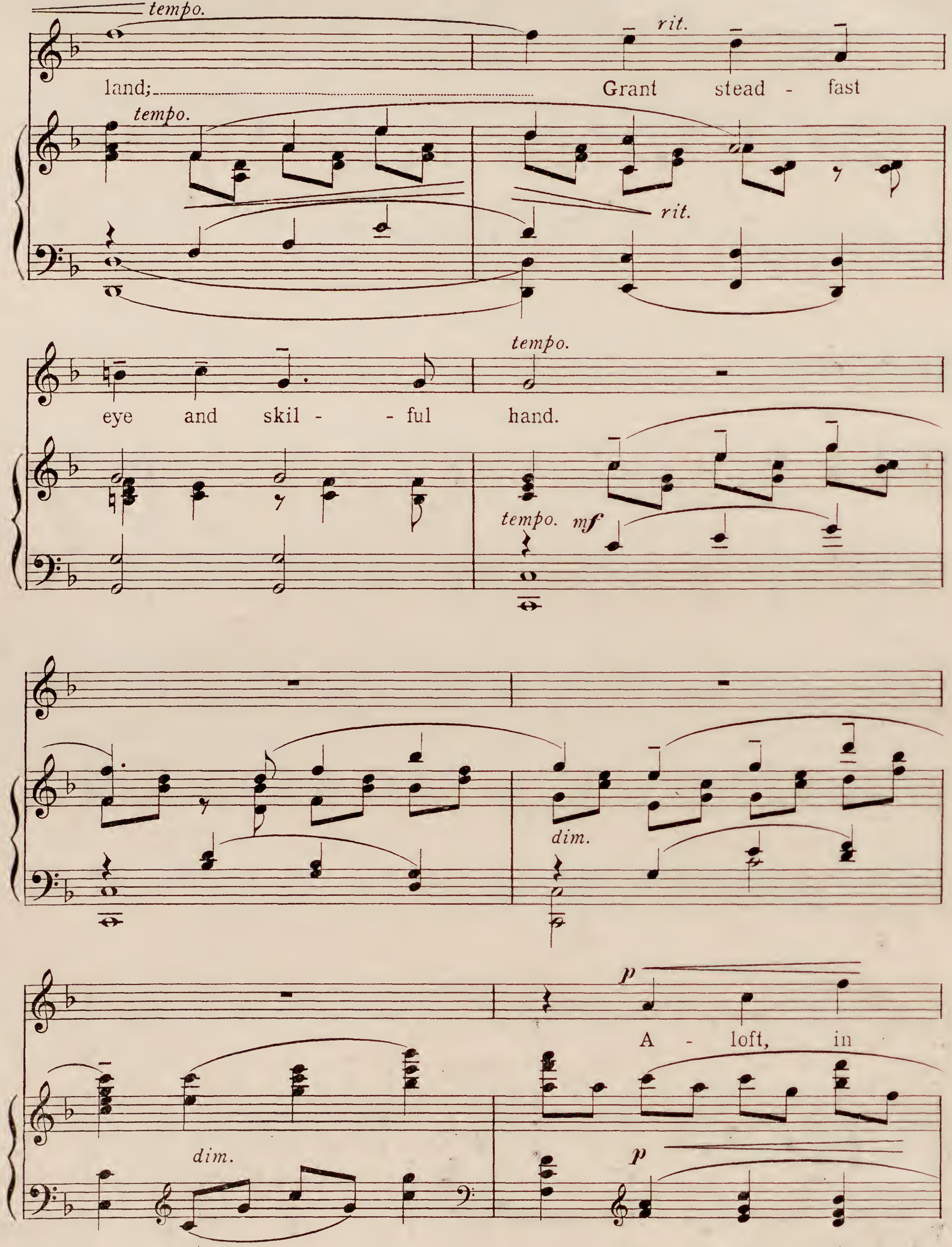

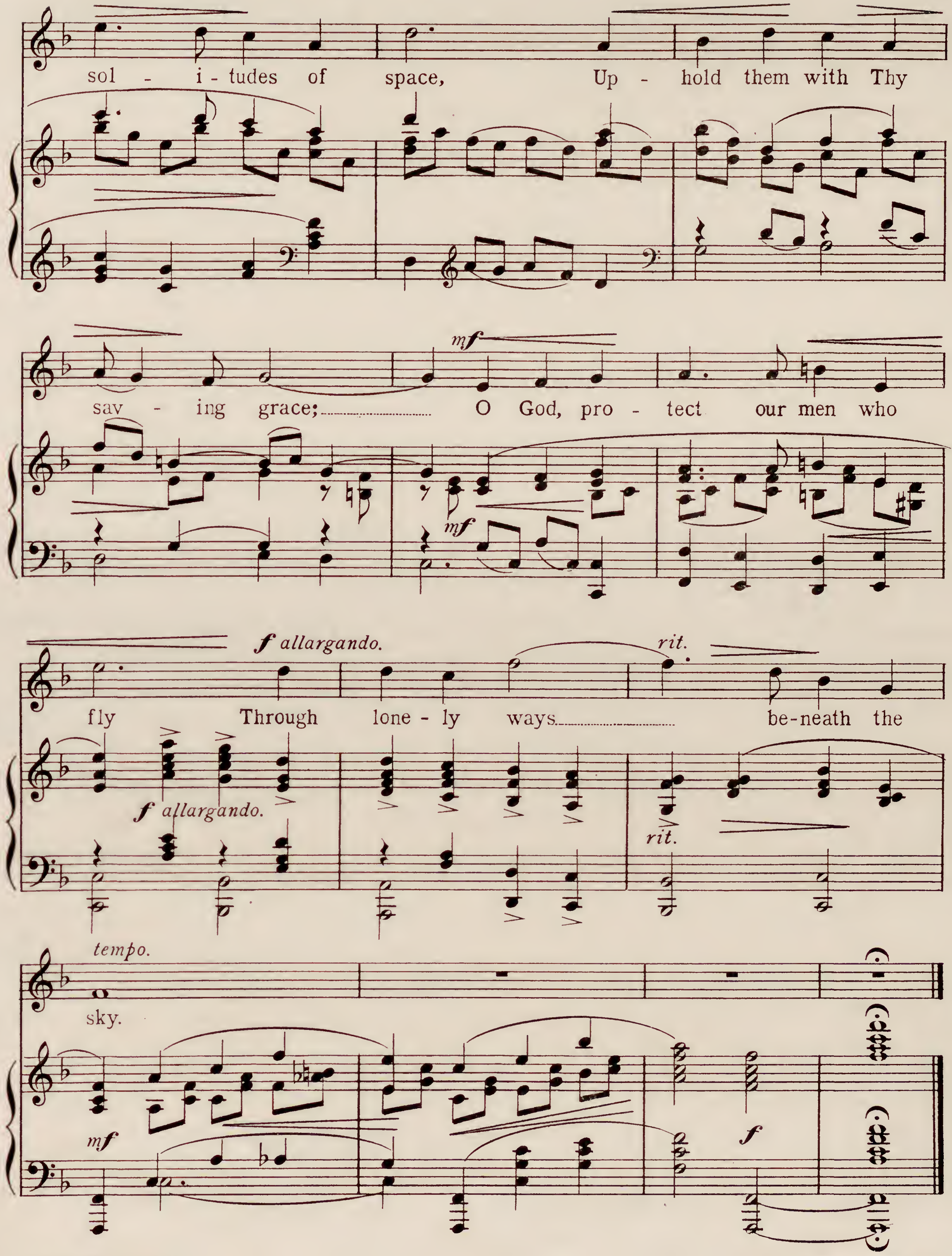


\section{BOOSEY \& CO.'S New and Standard Songs and Ballads.}

The Compass of the first Key only is given: from this the Compass of the other Keys ean be readily found.

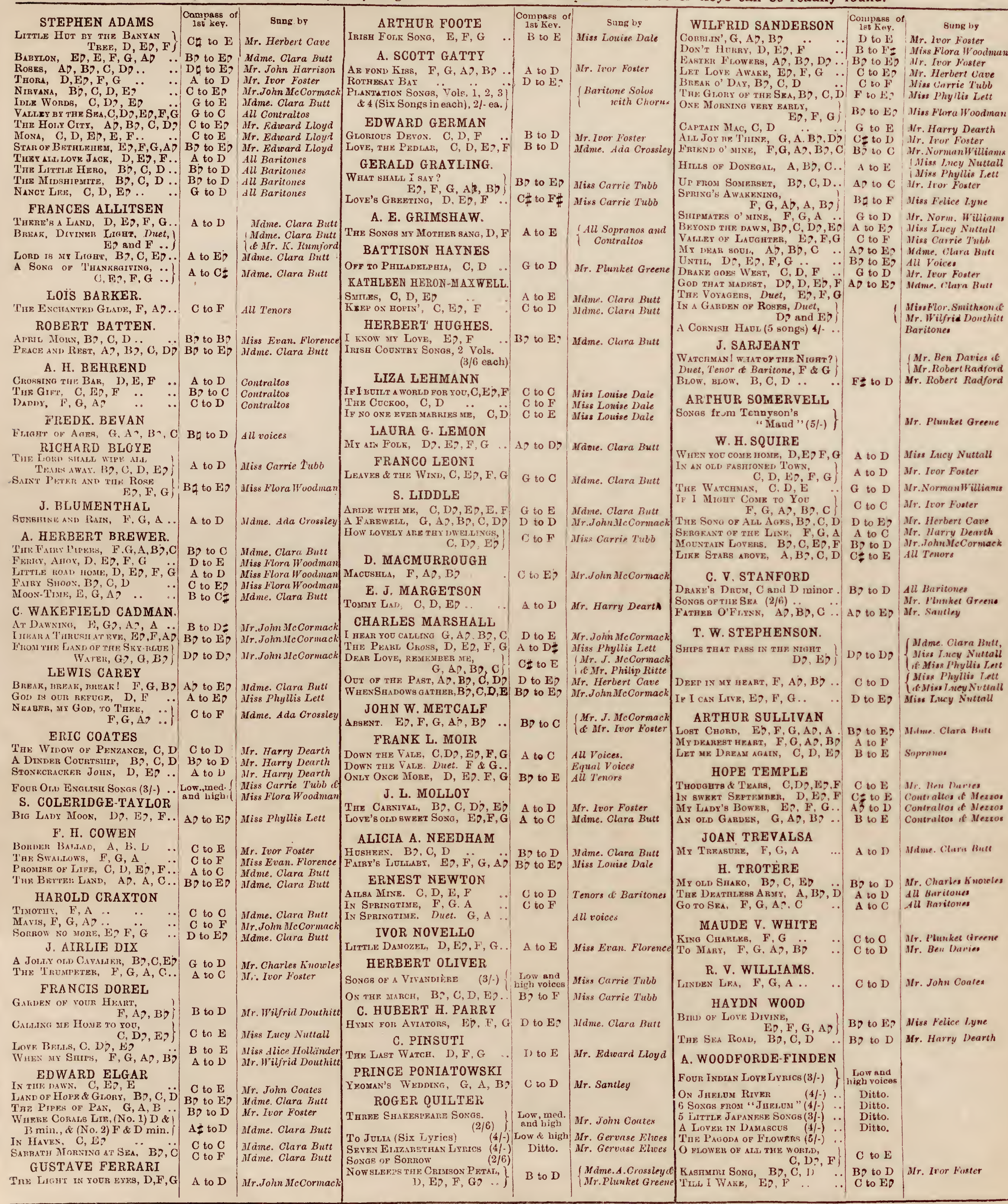

